\title{
The epidemiology and treatment of gout
}

This article was published in the following Dove Press journal:

Open Access Rheumatology: Research and Reviews

20 December 20II

Number of times this article has been viewed

\section{Neil W McGill \\ Institute of Rheumatology and Orthopaedics, Royal Prince Alfred Hospital, Camperdown, Sydney, Australia}

Correspondence: Neil W McGill Suite 315, RPA Medical Centre, 100 Carillon Ave, Newtown, NSW 2042, Australia

Tel +61295195131

Fax +6I 295172439

Email neil.mcgill@sswahs.nsw.gov.au

\begin{abstract}
The development and expression of gout depends on three key steps: (1) chronic hyperuricemia, (2) the growth of monosodium urate (MSU) crystals, and (3) interaction between MSU crystals and the inflammatory system. Epidemiological studies have continued to improve our understanding of the environmental and genetic factors which influence chronic hyperuricemia and gout. The influence of obesity, alcohol, race, sex, age, and specific dietary components will be discussed below. The primary mechanism of hyperuricemia is insufficient renal clearance of uric acid which in turn is dependent on transport of uric acid in the proximal renal tubule. Knowledge of the transport mechanisms has improved understanding of the genetic influences on gout and is relevant to understanding of the effects of drugs which can increase or decrease renal uric acid clearance. The application of established principles of management including diagnosis through crystal identification, the gradual introduction of hypouricemic therapy with the use of prophylaxis to reduce the risk of flares, identification of a suitably low target of plasma urate, a progressive increase in therapy to achieve the target and taking steps to encourage good compliance, has the potential to improve outcomes for patients with this very common affliction. The potential role for new therapies will also be discussed.
\end{abstract}

Keywords: gout, hyperuricemia, allopurinol, febuxostat, lesinurad, pegloticase

\section{The epidemiology and treatment of gout}

This review will initially address the epidemiology of gout and then discuss developments in the management of this very common disorder. An excellent review of the epidemiological studies relevant to gout has been recently published. ${ }^{1}$ The nomenclature used in this review is based on the fact that uric acid is a weak acid with a pKa of approximately 5.8 . Thus, in plasma it exists predominantly as the ionized urate ion. Logically therefore the plasma measurement should be referred to as "urate" rather than "uric acid". Plasma and serum urate concentrations are equivalent and in this review "plasma urate" will be used, regardless of whether the original publication used plasma or serum. The crystals which form in joints to produce gout are monosodium urate monohydrate (MSU), not uric acid, crystals. In acidic urine about 50\% of uric acid exists in its non-dissociated state and the crystals which may form in urine are composed of uric acid. Thus, when referring to urine or urinary calculi, the appropriate term is "uric acid".

The development of gout requires three distinct steps: (1) prolonged hyperuricemia, (2) formation of monosodium urate monohydrate (MSU) crystals and (3) interaction between MSU crystals and the inflammatory system. The epidemiology of gout closely mirrors that of prolonged hyperuricemia and although factors 
(other than urate concentration) which influence crystal formation $^{2}$ and interaction with the inflammatory system ${ }^{3,4}$ have been identified, variability of these factors between individuals has not yet been shown to have a major influence on the prevalence and expression of the disease.

\section{Change in prevalence over time}

Although the association between some conditions, such as obesity and race, and gout has been appreciated for many years, for others the association has been demonstrated more recently and the relative importance of various risk factors is yet to be clarified. In those parts of the world where adequate studies have occurred, the prevalence of gout has increased. This trend has been demonstrated in New Zealand, ${ }^{5}$ the US, ${ }^{6,7}$ China, ${ }^{8}$ and to a lesser extent, the UK. ${ }^{9}$ Studies performed in the last two decades have provided community prevalence rates of gout of about nine per 1000 (US), ${ }^{10}$ five $^{9}$ and $14^{11}$ per 1000 (UK), and five per 1000 (China). Much higher prevalence rates have been found in specific groups such as Maori (64 per 1000) $)^{5}$ and aboriginal Taiwanese (91 per 1000). ${ }^{12}$

\section{Risk factors for gout}

Although the relative importance of the risk factors discussed below has not been clearly established, they will be presented in an approximate order of their strength of association with the prevalence of gout.

\section{Plasma urate concentration}

An association between the plasma urate concentration and the prevalence and incidence of gout has been very clearly demonstrated. In the Normative Aging Study ${ }^{13}$ the 5-year cumulative incidence of gout rose from $<1 \%$ for plasma urate $<0.42 \mathrm{mmol} / \mathrm{L}$ to $30 \%$ for plasma urate $>0.60 \mathrm{mmol} / \mathrm{L}$ (Table 1). In a Taiwanese study the 5-year cumulative incidence of gout was $10.8 \%$ for plasma urate $0.42 \mathrm{mmol} / \mathrm{L}$ to $0.47 \mathrm{mmol} / \mathrm{L}, 27.7 \%$ for plasma urate $0.48 \mathrm{mmol} / \mathrm{L}$ to

Table I Relationship between plasma urate concentration and the incidence of gout in the Normative Aging Study ${ }^{14}$

\begin{tabular}{lll}
\hline $\begin{array}{l}\text { Plasma urate } \\
\text { (mmol/L) }\end{array}$ & $\begin{array}{l}\text { Incidence (per } \mathbf{1 0 0 0} \\
\text { human-years) }\end{array}$ & $\begin{array}{l}\text { 5-year cumulative } \\
\text { incidence } \mathbf{\%})\end{array}$ \\
\hline$<0.36$ & 0.8 & 0.5 \\
$0.36-0.41$ & 0.9 & 0.6 \\
$0.42-0.47$ & 4.1 & 2.0 \\
$0.48-0.53$ & 8.4 & 4.1 \\
$0.54-0.59$ & 43.2 & 19.8 \\
$>0.60$ & 70.2 & 30.5 \\
\hline
\end{tabular}

Adapted from Campion et al. Asymptomatic hyperuricemia. Risks and consequences in the Normative Aging Study. Am J Med. 1987;82(3):42I-426.

With permission from Elsevier.
$0.53 \mathrm{mmol} / \mathrm{L}$, and $61.1 \%$ for plasma urate $\geq 0.54 \mathrm{mmol} / \mathrm{L} .{ }^{14}$ Acute hyperuricemia, such as in the setting of chemotherapy for lymphoma or leukemia, generally does not produce gout, because of the lack of time required for MSU crystal formation. These patients are however potentially at risk of uric acid nephropathy.

\section{Sex}

Plasma urate levels and prevalence and incidence rates for gout are higher in men and post-menopausal women than in pre-menopausal women. ${ }^{15}$ The association between male sex and gout appears to be, at least predominantly, mediated via an effect on plasma urate levels although a minor independent (of plasma urate) effect has not been excluded. Many studies ${ }^{16-19}$ have presented prevalence rates based on the presence or absence of hyperuricemia but have used different cut-offs to define hyperuricemia in men (usually $>0.42 \mathrm{mmol} / \mathrm{L}$ ) and women (usually $>0.36 \mathrm{mmol} / \mathrm{L}$ ) thus obscuring the inter-relationship between gout, sex, and plasma urate concentration.

\section{Genetic factors}

The marked difference in prevalence rates between different racial groups living in the same country, such as Maori and Europeans in New Zealand and Aboriginal and non-Aboriginal Taiwanese, highlights the importance of genetic factors in the development of gout. As more than $90 \%$ of people with gout demonstrate under-excretion (rather than overproduction) of uric acid and renal excretion accounts for about $70 \%$ of the total (the remainder going via the bowel), renal handling of uric acid has been the focus of interest. Twin studies have shown a strong inherited effect on the renal handling of uric acid ${ }^{20}$ but demonstrated genetic associations account for only a small percentage $(<5 \%)$ of the variation of plasma urate levels. ${ }^{21}$ Human urate transporter 1 (URAT1) plays a key role in controlling uric acid reabsorption in the proximal renal tubule and alterations of the SLC22A12 gene, which codes for URAT1, have been shown to influence plasma urate levels. ${ }^{22,23}$ Polymorphisms of genes that code for other urate transporters (fructose and glucose transporter SLC2A9 (GLUT9) in the proximal tubule; sodium/ phosphate co-transporter SLC17A3 in the proximal tubule; urate efflux transporter ABCG2 in the proximal collecting duct) have also been shown to be associated with variations in the prevalence of hyperuricemia and gout. ${ }^{24,25}$

\section{Obesity}

A strong relationship has been demonstrated between increasing body mass index (BMI) and the risk of gout 
(relative risk [RR]: 3.0 for $\left.\mathrm{BMI}>35 \mathrm{~kg} / \mathrm{m}^{2}\right)^{26,27}$ and loss of weight has been shown to decrease the risk (multivariate RR: 0.6 for loss $>4.5 \mathrm{~kg}$ ). Increased exercise was associated with lower incidence of gout. ${ }^{28}$

\section{Alcohol intake}

Increased alcohol intake has been shown to be associated with an increased risk of gout in men and women. Heavy alcohol consumers ( $>196 \mathrm{~g}$, ie, $>20$ standard drinks per week) had an RR of 3.1 (women) and 2.2 (men) compared with those who consumed $<28 \mathrm{~g}$ (less than three standard drinks) per week. ${ }^{27}$ In the Health Professionals Follow-up Study, multivariate analysis provided an RR of 2.5 for developing gout for those who drank $\geq 50 \mathrm{~g} /$ day compared with those with no alcohol intake. A graded association between risk of gout and alcohol intake was found. ${ }^{29}$ The relative importance of different alcoholic beverages (beer, spirits, wine) remains uncertain due to conflicting findings with some studies suggesting greater importance for beer and spirits ${ }^{29}$ and others finding no difference. ${ }^{28}$

\section{Diet other than alcohol}

High meat and seafood intake have been found to modestly increase the incidence of gout with RR, after adjustment for age, BMI, diuretic use, hypertension, renal function and alcohol intake, of 1.4 (meat) and 1.5 (seafood) when comparing the highest and lowest quintiles. ${ }^{30}$ High fructose intake, mainly from corn syrup sweetened soft drinks and fruit juices, also increased the incidence of gout (RR: 1.8, highest vs lowest quintile). ${ }^{31}$ Fructose is a monosaccharide which can be ingested as free fructose and is also released from the digestion of sucrose in the small intestine. The total fructose intake is equal to the free fructose intake plus half the sucrose intake. The risk of gout associated with a fructose intake in the top quintile was comparable to that associated with an alcohol intake of 30-50 g per day. In countries such as Australia and New Zealand, where sucrose (cane sugar) is used as the sweetener, the importance of soft drink intake is likely to be less. ${ }^{32}$

Consumption of purine-rich vegetables was not associated with gout ${ }^{30}$ and dietary factors that appear to reduce the risk of gout include low-fat, but not high-fat, dairy products (RR: 0.58 , highest vs lowest quintile), vitamin C (RR: 0.55 , daily intake $>1500 \mathrm{mg}$ vs daily intake $<250 \mathrm{mg}$ ), ${ }^{33}$ and coffee. ${ }^{34}$

\section{Glucose intolerance and diabetes}

Strong cross-sectional associations have been demonstrated between hyperuricemia, gout, and metabolic syndrome. ${ }^{35-37}$
The association exists in the prediabetic state where increased insulin levels associated with insulin resistance influence plasma urate levels. When diabetes develops, the uricosuric effect of glycosuria results in reduced urate levels and reduced risk of future gout. The inverse association with the development of gout was stronger for type 1 than with type 2 diabetes. ${ }^{38}$

\section{Hypertension and renal disease}

Chronic renal disease has a major influence on the incidence and prevalence of gout with RRs in the 3-5 range. ${ }^{26}$

Hypertension increases the incidence of gout (multivariate RR: 1.5, 2.3, 1.6, and 1.8 compared with nonhypertensive subjects). ${ }^{11,26,27}$

\section{The effect of gout on other disorders}

\section{Glucose intolerance and diabetes}

Although diabetes reduces the likelihood of future gout, when the relationship has been has been studied in the reverse direction, gout in men with a high cardiovascular risk profile, was found to increase the future risk of type 2 diabetes, independent of BMI. ${ }^{39}$

\section{Hypertension and renal disease}

Gout increases the risk of death in renal dialysis patients. ${ }^{40}$ The coexistence of impaired renal function and gout has important implications for therapy. In most patients with this combination, the renal disease is not due to gout. ${ }^{41}$ Chronic gouty nephropathy, characterized histologically by MSU crystal granulomas with foreign body giant cells, interstitial fibrosis and vascular changes, has been reported in patients with chronic tophaceous gout but appears to be extremely rare in the absence of substantial tophaceous disease. It has been suggested that deterioration of renal function in patients with gout can usually be attributed to hypertension, diabetes or unrelated renal disease ${ }^{42}$ However, a randomized, nonblinded, prospective study of 59 patients with gout, which compared treatment with allopurinol + colchicine and colchicine alone over a 2-year period, found that $37 \%$ of the colchicine only group and $9 \%$ of the allopurinol + colchicine group experienced a deterioration of glomerular filtration rate $>10 \mathrm{~mL} /$ minute $/ 1.73 \mathrm{~m}^{2}{ }^{43}$ Thus, hyperuricemia has relatively little effect on renal function in most individuals but in patients with gout, allopurinol therapy may have some renal protective effect.

\section{Cardiovascular disease}

Gout is associated, independent of traditional cardiovascular risk factors, with a higher risk of death from all causes 
and the risk is primarily due to increased cardiovascular deaths. ${ }^{446}$ Whether hyperuricemia per se is independently associated with cardiovascular disease and mortality remains unclear with contradictory findings from published studies although the evidence in favor of an association has strengthened..$^{45-47}$

\section{Formation of monosodium urate monohydrate crystals}

The maximal speed of MSU crystal growth in vivo remains uncertain but, based on in vitro experiments, crystal growth appears to occur very slowly, over months. Although hyperuricemia is a requirement, most hyperuricemic individuals never grow crystals, and thus it is clear that other factors, such as those which promote/inhibit crystal nucleation and influence crystal growth play a role in determining whether and where crystal formation occurs. No modifiable factor other than the plasma urate concentration has been identified.

\section{Interaction between MSU crystals and the inflammatory system}

The typical presentation of acute gout is characterized by an abrupt onset of joint inflammation, often reaching maximal intensity within 24 hours. The great toe metatarsophalangeal joint is most commonly involved but involvement of the intertarsal, ankle and knee joints is also common, and patients with disease duration of many years often also have hand, wrist and olecranon bursal involvement. The acute clinical presentation is associated with a rapid increase in interaction between the inflammatory system and preformed MSU crystals. Even between attacks, there is evidence of low grade inflammation associated with intra-articular MSU crystals. $^{48}$

Following cell surface recognition by toll-like receptors 2 and 4, FC receptors, and integrins, MSU crystals are phagocytosed by monocytes or macrophages which results in NALP3 assembly, caspase-1 activation, cleavage of prointerleukin- $1 \beta$ and secretion of active interleukin-1 $\beta$ (IL-1). IL-1 activates other macrophages to produce tumor necrosis factor $\alpha$ (TNF), interleukin 6 and neutrophil chemotactants. An important role for IL-1 has been confirmed by the successful use of IL-1 inhibitors to treat refractory gout. ${ }^{49}$ The key role of neutrophils, recognized many years ago, has not been diminished by the new findings and it has now been established that the tyrosine kinase Tec plays a major role in the sequence of events leading to neutrophil influx. The interaction between MSU crystals and neutrophils leads to the production of IL-8, leukotriene B4, prostaglandin E2, and IL-1. MSU stimulation of osteoclastogenesis appears to play a role in bone erosion in gout. ${ }^{50}$

\section{Diagnosis of gout}

Acute crystal-induced arthritis due to MSU or calcium pyrophosphate dihydrate (CPPD) crystals can present in the same fashion as septic arthritis and cannot be reliably differentiated on the basis of blood white cell counts, raised inflammatory markers, or synovial fluid white cell counts. As the management is very different, failure to correctly differentiate these disorders poses a substantial risk. Submitting a patient with crystal-induced arthritis to an arthroscopic joint lavage, performed on the basis of presumed septic arthritis, can be detrimental. Although diagnostic criteria sets for gout are helpful for research, none is more than $70 \%$ sensitive or $89 \%$ specific. $^{51}$ The critical investigation is synovial fluid analysis. Gram stain for microorganisms and polarized light microscopy for the detection of crystals can both be performed immediately with no delay in obtaining the results, provided adequately trained personnel are available. Ensuring that laboratory personnel involved in the assessment of synovial fluid have the necessary skills is important. Surveys from around the world have demonstrated the relative lack of accuracy of synovial fluid examination for crystals. ${ }^{52-55}$ Synovial fluid examination quality assurance programs are currently available in Australia, New Zealand (both using real fluids) and the US (simulated fluids) and have been shown to improve performance. ${ }^{56}$

It is reasonable to provide treatment for probable acute gout in circumstances where synovial fluid cannot be obtained and the diagnosis is thus not certain but as drug therapy for the prevention of gout is usually required lifelong, near certainty of the diagnosis is warranted before commencing hypouricemic therapy. With careful attention to methodology and adequate practice, it is possible to aspirate fluid from great toe MTP and knee joints between attacks of gout in the majority. ${ }^{57}$ If it is possible to obtain fluid from a joint which has been previously affected by gout, provided the individual has not subsequently received prolonged hypouricemic therapy, then urate crystals can be identified in the great majority $(97 \%$ and $100 \%$ in separate studies). ${ }^{57}$ In patients with gout, aspiration of fluid from a previously uninvolved joint will demonstrate MSU crystals in about $25 \%$. Only a tiny sample of synovial fluid or material from a tophus is required but laboratory protocols to minimize the risk of needle stick injury can result in needles being discarded and hence the loss of potentially diagnostic aspirates. When very small amounts of fluid are 
expected, such as with aspiration from a great toe MTP joint, the aspiration is best performed where there is facility for immediate examination of the fluid.

The plasma urate concentration at the time of presentation with acute gout is not a useful diagnostic aid. Only approximately $25 \%$ of individuals with a plasma urate above $0.42 \mathrm{mmol} / \mathrm{L}$ ever develop gout. A raised plasma urate thus does not establish the diagnosis. At the time of presentation with acute gout, approximately $40 \%$ of individuals have a plasma urate below saturation. ${ }^{58,59}$ The mechanism by which the plasma urate concentration is lower at the time of acute gout than it is at subsequent follow-up, remains uncertain but it is clear that a plasma urate below saturation does not exclude the diagnosis of acute gout.

\section{Treatment of the acute episode of gout}

Effective options for the treatment of the acute attack include non-steroidal anti-inflammatory drugs (NSAIDs), intra-articular corticosteroids and systemic corticosteroid therapy. With respect to efficacy (although not toxicity) the rapidity with which therapy is commenced appears to be more important than which medication is used. The best choice is often determined by whether or not there are contraindications to NSAID use, such as renal or cardiac insufficiency or a history of peptic ulceration. Provided synovial fluid has been sent for analysis, including culture, it is reasonable to administer intra-articular corticosteroid immediately following joint aspiration (without removing the needle from the joint) when gout appears likely, even though sepsis has not yet been excluded. Systemic corticosteroid therapy can be provided as oral prednisone $20-40 \mathrm{mg}$ daily in divided doses reducing to zero in 10-14 days or intramuscular depot tetracosactrin $1 \mathrm{mg}$, a synthetic analog of ACTH. ${ }^{60}$ Despite widespread acceptance of systemic corticosteroid therapy, controlled trials have been of only moderate to low quality such that a Cochrane review determined that there was inconclusive evidence of efficacy and effectiveness. ${ }^{61}$

Colchicine used as the primary treatment of the acute attack is associated with a very high rate of gastrointestinal toxicity. ${ }^{62,63}$ A lower dose regime, consisting of colchicine $1.2 \mathrm{mg}$ initially and a further $0.6 \mathrm{mg}$ after 1 hour, was associated with much reduced toxicity but efficacy for both high and low-dose colchicine was poor with $\geq 50 \%$ pain reduction at 24 hours attained by only $38 \%$ (low dose) and 33\% (high dose) of patients with an acute gout flare. ${ }^{64}$ Particular care in the use of colchicine is required in the setting of renal failure and co-prescription of inhibitors of cytochrome P450 3A4 such as cyclosporine, pravastatin, azithromycin, and clarithromycin. ${ }^{65-67}$
Because of their expense, biological therapies in gout appear likely to have a limited clinical role but they offer the chance of better understanding of the mechanisms involved. As discussed above IL-1 plays an important role in gouty inflammation. The IL-1 receptor antagonist, anakinra ${ }^{49}$ and other biological therapies which inhibit IL-1 (rilonacept, canakinumab) have been shown to effectively suppress acute gouty inflammation. ${ }^{68}$ Anti-TNF therapy has also been reported to be of benefit in a case report. ${ }^{69}$

\section{Prophylactic therapy}

The aim of prophylactic therapy is to prevent acute attacks, to prevent joint/bone damage and to prevent other sequelae of tophi, such as tendon disease. To achieve these aims it is vital that the plasma urate level be maintained at a sufficiently low level. The evidence supporting the relationship between lower plasma urate levels during treatment and better outcomes for patients with gout, including fewer flares, faster reduction in tophi, and depletion of MSU crystals in synovial fluid, is strong. ${ }^{70}$ How low is low enough? The British Society for Rheumatology guidelines, ${ }^{71}$ published in 2007, recommended $<0.30 \mathrm{mmol} / \mathrm{L}$ whereas the European League Against Rheumatism (EULAR) guidelines, ${ }^{72}$ published in 2006 , recommended $<0.36 \mathrm{mmol} / \mathrm{L}$. Recommendations from the US generally aim for $<0.36 \mathrm{mmol} / \mathrm{L}(6 \mathrm{mg} / 100 \mathrm{~mL}){ }^{73}$ Clinical outcomes are worse for patients with higher plasma urate levels. ${ }^{70}$ A reasonable conclusion, based on the currently available data, would be that the plasma urate should at least be maintained $<0.36 \mathrm{mmol} / \mathrm{L}$, but $<0.30 \mathrm{mmol} / \mathrm{L}$ is probably even better if it can be achieved without compromising compliance or safety. Strategies that can be used to reduce plasma urate should be considered in the knowledge that lack of compliance is a very common cause of treatment failure. A recent study of almost 10,000 people in the US found that $64 \%$ were poorly compliant with hypouricemic therapy during a 1-year period. ${ }^{74}$ In another very large study, compliance with therapy for gout (37\%) was poorer than with therapy for hypertension (72\%), hypothyroidism (68\%), type 2 diabetes (65\%), seizure disorders (61\%), hypercholesterolemia (55\%), and osteoporosis $(51 \%) .{ }^{75}$ Clear explanation of the rationale of therapy, a focus on the most important measures, and adequate follow-up including measurement of plasma urate are likely to improve compliance.

\section{Non-drug interventions}

Unfortunately, lifestyle modification rarely leads to more than a $15 \%$ reduction in plasma urate and thus is of limited efficacy with respect to achieving the target plasma urate concentration. 
Correction of obesity and alcohol reduction have general health benefits separate from their effect on gout and are usually appropriate to encourage. Based on the epidemiological studies discussed above, dietary modification to increase regular low fat milk or yoghurt, vegetable sources of protein, cherries and coffee, and to decrease intake of liver, kidneys, shellfish, seafood, yeast extracts, total protein, and red meat would appear reasonable. ${ }^{71}$ Before requesting substantial lifestyle modification, clinicians should consider the likelihood of benefit and the risk that increasing the complexity of treatment may reduce compliance with effective drug therapies. To the author's knowledge, no prospective long-term intervention study has demonstrated success from the lifestyle modifications described.

\section{Drug interventions Drug cessation}

When possible, cessation of drugs that increase the urate concentration is desirable. The use of diuretic therapy for hypertension represents a situation where good alternatives are usually available and cessation of diuretic therapy may be sufficient to return the plasma urate below saturation. Losartan and fenofibrate have weak uricosuric effects and thus may be worth considering in the patient with gout, if there is another indication.

\section{Allopurinol}

Allopurinol remains the most important hypouricemic drug worldwide, accounting for more than $98 \%$ of prescriptions for urate lowering therapy in Australia. ${ }^{76}$ Allopurinol (half-life 1-2 hours) is rapidly metabolized to oxypurinol (half-life 18-30 hours). They are analogs of hypoxanthine and xanthine respectively, and inhibit xanthine oxidase, the enzyme which catalyzes the conversion of hypoxanthine to xanthine and xanthine to uric acid. Surveys of the use of allopurinol have highlighted the frequency of suboptimal use of this agent. ${ }^{77}$ The introduction of hypouricemic therapy is associated with a temporary increase in the risk of a flare of gout. The risk can be reduced by a gradual (rather than abrupt) fall in the plasma urate ${ }^{78}$ and thus allopurinol should be introduced at low dose (eg, $100 \mathrm{mg} /$ day) and increased every few weeks in an attempt to have the urate level fall by $<0.04 \mathrm{mmol} / \mathrm{L} /$ month. The concurrent use of low-dose colchicine (see below for precautions) further reduces the risk of a flare. ${ }^{79}$ Failure to adequately progressively increase the dose is common. The vast majority of allopurinol prescriptions are for doses of $300 \mathrm{mg} /$ day or less ${ }^{77}$ and yet only $24 \%$ of patients who received allopurinol $300 \mathrm{mg} /$ day achieved a plasma urate at or below $0.30 \mathrm{mmol} / \mathrm{L} .{ }^{80} \mathrm{In}$ another study of patients who initially had a plasma urate of $0.48 \mathrm{mmol} / \mathrm{L}$ or more, only $21 \%$ achieved a plasma urate $<0.36 \mathrm{mmol} / \mathrm{L}$ while receiving allopurinol $300 \mathrm{mg} /$ day. ${ }^{81}$ By progressively increasing the allopurinol dose, the percentage of patients achieving a target of $<0.30 \mathrm{mmol} / \mathrm{L}$ increased to $78 \%{ }^{82}$

Failure to increase the allopurinol dose has occurred, at least in part, in response to attempts to minimize the risk of allopurinol hypersensitivity syndrome, a severe and not infrequently fatal disorder. The syndrome is rare, with estimates of one in $56,000^{83}$ and one in $1000^{84}$ reported. In 1984, Hande et al ${ }^{85}$ reported 78 cases (six new and 72 from the literature) of the syndrome and noted an association with renal insufficiency. It was suggested that the dose of allopurinol be reduced in proportion to creatinine clearance and that the reduced doses recommended "should be adequate to inhibit uric acid production in most patients." The impact of those recommendations appears to have been large and has resulted in inadequate reduction of plasma urate ${ }^{86}$ In the setting of renal insufficiency, allopurinol doses sufficient to produce plasma oxypurinol levels above the proposed therapeutic range result in a higher percentage of patients reaching the target plasma urate. ${ }^{87}$

The severity of the allopurinol hypersensitivity syndrome should be emphasized. A mortality rate of $18 \%$ was reported in a recent series and an association with renal impairment and increased age was found. ${ }^{88}$ More than $95 \%$ of cases occur within 6 weeks of commencement of allopurinol. ${ }^{85,89}$ It can occur in all age groups and in patients with normal renal function. Despite the apparent association with renal impairment, no increase in the prevalence of adverse reactions to allopurinol was seen in patients who received higher maintenance doses..$^{90}$ The development of a rash in the setting of allopurinol therapy, especially if the duration of therapy has been less than 12 weeks, should prompt urgent consideration of allopurinol hypersensitivity, regardless of the patient's age and renal function.

The use of azathioprine or 6-mercaptopurine with a xanthine oxidase inhibitor (allopurinol or febuxostat) is dangerous and should only be contemplated in rare situations after careful consultation.

A reasonable approach to the use of allopurinol is to start at low dose $(100 \mathrm{mg} /$ day, less if previous attempts have failed due to flares in the introductory period), to be alert to symptoms of hypersensitivity especially in the first 6 weeks, and to increase the dose approximately every month while monitoring plasma urate, aiming to achieve a gradual fall to $<0.36 \mathrm{mmol} / \mathrm{L}$ (if $<0.30 \mathrm{mmol} / \mathrm{L}$ can be 
achieved that may be even better). Substantial fluctuations in the plasma urate suggest variable compliance and should prompt further discussion and education before any increase in dosage is recommended. The dose should be gradually increased (600 mg/day is not uncommonly required and up to $900 \mathrm{mg}$ /day is occasionally required) to achieve target. In the setting of renal insufficiency, the same approach is followed with dosage increments of $100 \mathrm{mg}$ /day or less but once the plasma urate has reached a plateau there is no advantage in further increasing the dose of allopurinol. It is usually appropriate to use prophylaxis to reduce the risk of a flare during the introductory phase. Depending on comorbidities, low-dose colchicine ( $0.5 \mathrm{mg}$ bd), NSAID or COX2 inhibitor, or low-dose prednisone may be used for this purpose.

For patients who are allergic to or intolerant of allopurinol, the options will be influenced by medication availability in that country.

\section{Probenecid}

If the patient has adequate renal function (GFR $>30-40 \mathrm{~mL} /$ minute) probenecid, a uricosuric drug which inhibits URAT1 in the proximal renal tubule, is often appropriate. Because of the increased urinary excretion of uric acid which is most marked in the early phase of treatment, good hydration is required and urinary alkalinization is appropriate. Previous renal calculi, particularly uric acid calculi, are a relative contraindication. As is true for all urate lowering therapy, the aim should be to achieve a gradual fall in plasma urate and to achieve target. A reasonable starting dose is $250 \mathrm{mg}$ (half tablet) twice daily. Maximal dose is $1 \mathrm{~g}$ twice daily.

\section{Febuxostat}

Febuxostat represents a major advance for allopurinolintolerant patients with poor renal function. Febuxostat inhibits the same enzyme as allopurinol (xanthine oxidase) but unlike allopurinol, is not a purine analog. After oral administration it is rapidly absorbed (84\%) with a half-life of 4-18 hours. It undergoes hepatic metabolism and no modification of dose is required in relation to renal function or age.

It is very effective $-93 \%$ of patients who tolerated the medication and continued for 5 years achieved a maintenance plasma urate $<0.36 \mathrm{mmol} / \mathrm{L} .{ }^{91}$ In a 28 -day study, $0 \%$ (placebo), $56 \%$ (40 mg/day), 76\% (80 mg/day), and 94\% (120 mg/day) of patients achieved plasma urate $<0.36 \mathrm{mmol} / \mathrm{L} .{ }^{92}$ Gout flares occurred more commonly in the $80 \mathrm{mg} /$ day (43\%) and $120 \mathrm{mg} /$ day $(55 \%)$ groups without prophylaxis but in only $8 \%-13 \%$ with colchicine prophylaxis $(0.6 \mathrm{mg}$ twice daily). In patients with at least reasonable renal function (plasma creatinine $<133 \mu \mathrm{mol} / \mathrm{L}$ or eGFR $>50 \mathrm{~mL} /$ minute/ $1.73 \mathrm{~m}^{2}$ ), who received treatment for 1 year, a target plasma urate of $<0.36 \mathrm{mmol} / \mathrm{L}$ was achieved by $53 \%$ (febuxostat $80 \mathrm{mg}$ /day), 62\% (febuxostat $120 \mathrm{mg} /$ day), and $21 \%$ (allopurinol $300 \mathrm{mg} /$ day). It should be noted that allopurinol dosing in this study was suboptimal and thus the relative efficacies of the therapies do not represent what could be achieved in practice.

The safety of febuxostat appears good. Concerns were raised in regard to cardiovascular events, leading to the recommendation that the drug be avoided in patients with a history of atherosclerotic disease, myocardial infarction or congestive heart failure. ${ }^{93}$ Data subsequently presented to the US Food and Drug Administration, ${ }^{94}$ including the results of the CONFIRMS study, did not identify any increase in cardiovascular events. Elevation of hepatic transaminases was uncommon and of similar frequency in the allopurinol and febuxostat groups. Most patients who have previously experienced severe adverse effects with allopurinol are able to successfully use febuxostat although allergy to both compounds is not rare. ${ }^{95}$

\section{Benzbromarone}

Benzbromarone is a potent uricosuric drug which has limited availability due to its withdrawal by the manufacturer on the basis of liver toxicity. The appropriateness of the withdrawal appears questionable ${ }^{83}$ and the superiority of benzbromarone over probenecid for patients who had failed to reach target with allopurinol, has recently been confirmed.$^{80}$ For selected patients, such as those with allergy to allopurinol and febuxostat and insufficient renal function for probenecid, benzbromarone is often appropriate with careful monitoring of liver function.

\section{Uricase}

Uricase (urate oxidase) catalyzes the conversion of urate to allantoin, which is $5-10$ times more soluble than urate and is easily excreted by the kidneys. The enzyme is active in most fish, amphibians, and non-primate mammals but not in man and higher primates. The infusion of recombinant Aspergillus uricase (rasburicase) leads to a rapid and profound reduction in plasma urate, an effect of benefit in the prevention and treatment of chemotherapy-induced hyperuricemia. ${ }^{96}$ Rasburicase has also been used for the treatment of tophaceous gout ${ }^{97}$ and sometimes results in a rapid reduction in the volume of tophi but its use is limited by the brevity of effect after each infusion, frequency of gout flares during therapy, allergic reactions to the protein, 
and expense. The conjugation of uricase to polyethylene glycol (pegloticase) allows a more sustained action with a half-life of uricase activity of 6.4 to 13.8 days. ${ }^{68}$ Protocols using pegloticase $8 \mathrm{mg}$ every 2 or 4 weeks have been shown to effectively maintain plasma urate below target over periods of up to 6 months. ${ }^{98}$ Gout flares, infusion reactions and a reduction in pegloticase half-life in association with anti-pegloticase antibodies were all common. Despite these difficulties, pegloticase may be useful for a small percentage of patients for whom other options are unavailable due to drug intolerance and/or renal insufficiency.

\section{Future drug options}

A spin-off from the development of the anti-retroviral nonnucleoside reverse transcription inhibitor RDEA806, has been the recognition that its active metabolite, lesinurad (RDEA594) is a potent uricosuric agent. Studies of lesinurad in gout are underway. ${ }^{68}$

\section{Summary}

Epidemiological studies continue to improve our understanding of factors which influence chronic hyperuricemia and gout. Successful long-term management of gout requires certainty of diagnosis through crystal identification, gradual introduction of hypouricemic therapy and the use of prophylaxis to reduce the risk of flares, identification of a suitably low target of plasma urate (well below saturation, at least $<0.36 \mathrm{mmol} / \mathrm{L}$ and preferably $<0.30 \mathrm{mmol} / \mathrm{L}$ ), and a willingness to progressively increase therapy to achieve the target. Achieving good compliance with drug therapy has the potential to produce large benefits and yet compliance with therapy for gout is much poorer than for other chronic conditions. The fault may lie as often with the physician as with the patient. In the absence of a clearly stated target and regular measurement of plasma urate is it reasonable to expect the patient to achieve good compliance with therapy? Allopurinol remains the most important urate-lowering drug.

Hypersensitivity reactions, although rare, are serious and more frequent in those with renal insufficiency. They almost always occur within the first 3 months of therapy and should not dissuade a gradual increase in allopurinol dose provided the plasma urate falls with each increase. Febuxostat, a nonpurine xanthine oxidase inhibitor, is of benefit for allopurinolintolerant patients and may achieve a widespread role due to its efficacy and lack of need for dose modification in mild or moderate renal insufficiency. For the small percentage of patients who cannot be successfully managed with currently available options the development of new therapies is likely to help.
The prospects for improved outcomes in this very common disease are good but will depend primarily on the widespread application of treatment approaches which have already been established.

\section{Disclosure}

The author reports no conflicts of interest in this work.

\section{References}

1. Roddy E, Doherty M. Epidemiology of gout. Arthritis Res Therapy. 2010;12(6):223.

2. McGill NW, Dieppe PA. The role of serum and synovial fluid components in promotion of urate crystal formation. J Rheumatol. 1991;18(7): 1042-1045.

3. Pope RM, Tschopp J. The role of interleukin-1 and the inflammasome in gout. Implications for therapy. Arthritis Rheum. 2007;56(10):3183-3188.

4. Popa-Nita O, Marois L, Paré G, Naccache PH. Crystal-induced neutrophil activation: X. Proinflammatory role of the tyrosine kinase Tec. Arthritis Rheum. 2008;58(6):1866-1876.

5. Klemp P, Stansfield SA, Castle B, Robertson MC. Gout is on the increase in New Zealand. Ann Rheum Dis. 1997;56(1):22-26.

6. Wallace KL, Riedel AA, Joseph-Ridge N, Wortmann R. Increasing prevalence of gout and hyperuricemia over 10 years among older adults in a managed care population. J Rheumatol. 2004;31(8):1582-1587.

7. Weaver AL. Epidemiology of gout. Cleve Clin J Med. 2008;75 Suppl 5: S9-S12.

8. Miao Z, Li C, Chen Y, et al. Dietary and lifestyle changes associated with high prevalence of hyperuricemia and gout in the Shandong coastal cities of Eastern China. J Rheumatol. 2008;35(9):1859-1864.

9. Elliot AJ, Cross KW, Fleming DM. Seasonality and trends in the incidence and prevalence of gout in England and Wales 1994-2007. Ann Rheum Dis. 2009;68(11):1728-1733.

10. Lawrence RC, Helmick CG, Arnett FC, et al. Estimates of the prevalence of arthritis and selected musculoskeletal disorders in the United States. Arthritis Rheum. 1998;41(5):778-799.

11. Mikuls TR, Farrar JT, Bilker WB, Fernandes S, Schumacher HR Jr, Saag KG. Gout epidemiology: results from the UK General Practice Research Database,1990-1999. Ann Rheum Dis. 2005;64(2):267-272.

12. Chang SJ, Ko YC, Wang TN, Chang FT, Cinkotai FF, Chen CJ. High prevalence of gout and related risk factors in Taiwan's Aborigines. J Rheumatol. 1997;24(7):1364-1369.

13. Campion EW, Glynn RJ, DeLabry LO. Asymptomatic hyperuricemia. Risks and consequences in the Normative Aging Study. Am J Med. 1987;82(3):421-426.

14. Lin KC, Lin HY, Chou P. The interaction between uric acid level and other risk factors on the development of gout among asymptomatic hyperuricemic men in a prospective study. J Rheumatol. 2000;27(6): 1501-1505.

15. Hall AP, Barry PE, Dawber TR, McNamara PM. Epidemiology of gout and hyperuricemia. A long-term population study. Am J Med. 1967;42(1):27-37.

16. Brauer GW, Prior IA. A prospective study of gout in New Zealand Maoris. Ann Rheum Dis. 1978;37(5):466-472.

17. Zimmet PZ, Whitehouse S, Jackson L, Thoma K. High prevalence of hyperuricaemia and gout in an urbanised Micronesian population. $\mathrm{Br}$ Med J. 1978;1(6122):1237-1239.

18. Rose BS, Prior IA, Davidson F. Gout and hyperuricaemia in New Zealand and Polynesia. Excerpta Med (Int Congreee Ser). 1968;148:344-353.

19. O'Sullivan JB. The incidence of gout and related uric acid levels in Sudbury, Massachusetts. Excerpta Med (Int Congreee Ser). 1968;148: 371-376.

20. Emmerson BT, Nagel SL, Duffy DL, Martin NG. Genetic control of the renal clearance of urate: a study of twins. Ann Rheum Dis. 1992;51(3): 375-377. 
21. van der Harst P, Bakker SJ, de Boer RA, et al. Replication of the five novel loci for uric acid concentrations and potential mediating mechanisms. Hum Mol Genet. 2010;19(2):387-395.

22. Graessler J, Graessler A, Unger S, et al. Association of the human urate transporter 1 with reduced renal uric acid excretion and hyperuricemia in a German Caucasian population. Arthritis Rheum. 2006;54(1): 292-300.

23. Taniguchi A, Urano W, Yamanaka M, et al. A common mutation in an organic anion transporter gene, SLC22A12, is a suppressing factor for the development of gout. Arthritis Rheum. 2005;52(8):2576-2577.

24. Dehghan A, Kottgen A, Yang Q, et al. Association of three genetic loci with uric acid concentration and risk of gout: a genome-wide association study. Lancet. 2008;372(9654):1953-1961.

25. Vitart V, Rudan I, Hayward C, et al. SLC2A9 is a newly identified urate transporter influencing serum urate concentration, urate excretion and gout. Nat Genet. 2008;40(4):437-442.

26. Choi HK, Atkinson K, Karlson EW, Curhan G. Obesity, weight change, hypertension, diuretic use, and the risk of gout in men: the health professionals follow-up study. Arch Intern Med. 2005;165(7):742-748.

27. Bhole V, de Vera M, Rahman MM, Krishnan E, Choi H. Epidemiology of gout in women: Fifty-two-year followup of a prospective cohort. Arthritis Rheum. 2010;62(4):1069-1076.

28. Williams PT. Effects of diet, physical activity and performance, and body weight on incident gout in ostensibly healthy, vigorously active men. Am J Clin Nutr. 2008;87(5):1480-1487.

29. Choi HK, Atkinson K, Karlson EW, Willett W, Curhan G. Alcohol intake and risk of incident gout in men: a prospective study. Lancet. 2004;363(9417):1277-1281.

30. Choi HK, Liu S, Curhan G. Intake of purine-rich foods, protein, and dairy products and relationship to serum levels of uric acid: the Third National Health and Nutrition Examination Survey. Arthritis Rheum. 2005;52(1):283-289.

31. Choi HK, Curhan G. Soft drinks, fructose consumption, and the risk of gout in men: prospective cohort study. BMJ. 2008;336(7639):309-312.

32. Underwood M. Sugary drinks, fruit, and increased risk of gout. Dietary fructose could be a contributing factor. BMJ. 2008;336(7639):285-286.

33. Choi HK, Gao X, Curhan G. Vitamin C intake and the risk of gout in men: a prospective study. Arch Intern Med. 2009;169(5):502-507.

34. Choi HK, Willett W, Curhan G. Coffee consumption and risk of incident gout in men: a prospective study. Arthritis Rheum. 2007;56(6):2049-2055.

35. Fam AG. Gout, diet and the insulin resistance syndrome. J Rheumatol. 2002;29(7):1350-1355.

36. Choi HK, Ford ES. Prevalence of the metabolic syndrome in individuals with hyperuricemia. Am J Med. 2007;120(5):442-447.

37. Choi HK, Ford ES, Li C, et al. Prevalence of the metabolic syndrome in patients with gout: the Third National Health and Nutrition Examination Survey. Arthritis Rheum. 2007;57(1):109-115.

38. Rodriguez G, Soriano LC, Choi HK. Impact of diabetes against the future risk of developing gout. Ann Rheum Dis. 2010;69(12):2090-2094.

39. Choi HK, De Vera MA, Krishnan E. Gout and the risk of type 2 diabetes among men with a high cardiovascular risk profile. Rheumatology. 2008;47(10):1567-1570.

40. Cohen SD, Kimmel PL, Neff R, Agodoa L, Abbott KC. Association of incident gout and mortality in dialysis patients. J Am Soc Nephrol. 2008;19(11):2204-2210.

41. Steele TH. Hyperuricemic nephropathies. Nephron. 1999;81 Suppl 1: 45-49.

42. Yu TSF, Berger L, Dorph DJ, Smith H. Renal function in gout. V. Factors influencing the renal haemodynamics. Am J Med. 1979;67(5):766-771.

43. Gibson T, Rodgers V, Potter C, Simmonds HA. Allopurinol treatment and its effect on renal function in gout: a controlled study. Ann Rheum Dis. 1982;41(1):59-65.

44. Choi HK, Curhan G. Independent impact of gout on mortality and risk for coronary heart disease. Circulation. 2007;116(8):894-900.

45. Strasak A, Ruttmann E, Brant L, et al. Serum uric acid and risk of cardiovascular mortality: a prospective long-term study of 83,683 Austrian men. Clin Chemistry. 2008;54(2):273-284.
46. Kuo CF, See LC, Luo SF, et al. Gout: an independent risk factor for all-cause and cardiovascular mortality. Rheumatology (Oxford). 2010; 49(1):141-146.

47. Gaffo AL, Edwards NL, Saag KG. Gout. Hyperuricemia and cardiovascular disease: how strong is the evidence for a causal link? Arthritis Res Ther. 2009;11(4):240.

48. Pascual E. Analysis of synovial fluid from healthy knees. Comparison with fluid from asymptomatic knees in RA, SLE and gout. $\mathrm{Br} J$ Rheumatol. 1992;31 Suppl 2:219.

49. McGonagle D, Tan AL, Shankaranarayana S, Madden J, Emery P, McDermott MF. Management of treatment resistant inflammation of acute on chronic tophaceous gout with anakinra. Ann Rheum Dis. 2007;66(12):1683-1684.

50. Dalbeth N, Smith T, Nicolson B, et al. Enhanced osteoclastogenesis in patients with tophaceous gout: urate crystals promote osteoclast development through interaction with stromal cells. Arthritis Rheum. 2008;58(6):1854-1865.

51. Malik A, Schumacher HR, Dinnella JE, Clayburne GM. Clinical diagnostic criteria for gout: comparison with the gold standard of synovial fluid crystal analysis. J Clin Rheumatol. 2009;15(1):22-24.

52. Von Essen R, Hölttä AM, Pikkarainen R. Quality control of synovial fluid crystal identification. Ann Rheum Dis. 1998;57(2):107-109.

53. McGill NW, York HF. Reproducibility of synovial fluid examination for crystals. Aust N Z J Med. 1991;21(5):710-713.

54. Schumacher HR, Sieck MS, Rothfuss S, et al. Reproducibility of synovial fluid analyses. A study among four laboratories. Arthritis Rheum. 1986;29(6):770-774.

55. Hasselbacher P. Variation in synovial fluid analysis by hospital laboratories. Arthritis Rheum. 1987;30(6):637-642.

56. McGill NW, McGill VG. Synovial fluid examination for crystals. A 7 year continuous quality assurance program. Intern Med J. 2006; 36 Suppl 2:A28.

57. Pascual E, Doherty M. Aspiration of normal or asymptomatic pathological joints for diagnosis and research: indications, technique and success rate. Ann Rheum Dis. 2009;68(1):3-7.

58. Schlesinger N, Baker DG, Schumacher HR. Serum uric acid during bouts of acute gouty arthritis. J Rheumatol. 1997;24(11):2265-2266.

59. Logan JA, Morrison E, McGill PE. Serum uric acid in acute gout. Ann Rheum Dis. 1997;56(11):696-697.

60. Schlesinger N. Overview of the management of acute gout and the role of adrenocorticotrophic hormone. Drugs. 2008;68(4):407-415.

61. Janssens HJ, Lucassen PL, Van de Laar FA, Janssen M, Van de Lisdonk EH. Systemic corticosteroids for acute gout. Cochrane Database Syst Rev. 2008;2:CD005521.

62. Ahern MJ, McCredie M, Reid C, Brooks PM, Gordon TP, Jones M. Does colchicine work? The results of the first controlled study in acute gout. Aust N Z J Med. 1987;17(3):301-304.

63. Nuki G. Colchicine: its mechanism of action and efficacy in crystalinduced inflammation. Curr Rheumatol Rep. 2008;10(3):218-227.

64. Terkeltaub RA, Furst DE, Bennett K, Kook KA, Crockett RS, Davis MW. High versus low dosing of oral colchicine for early acute gout flare: Twenty-four-hour outcome of the first multicentre, randomized, double-blind, placebo-controlled, parallel-group, dose-comparison colchicine study. Arthritis Rheum. 2010;62(4): 1060-1068.

65. Eleftheriou G, Bacis G, Fiocchi R, Sebastiano R. Colchicine-induced toxicity in a heart transplant patient with chronic renal failure. Clin Toxicol (Phila). 2008;46(9):827-830.

66. Adverse Drug Reactions Advisory Committee. Fatal interactions and reactions with colchicine: beware CYP3A4 inhibitors. Aust Adverse Drug Reactions Bull. 2008;27(5):2.

67. Bouquié R, Deslandes G, Renaud C, Dailly E, Haloun A, Jolliet P. Colchicine-induced rhabdomyolysis in a heart/lung transplant patient with concurrent use of cyclosporine, pravastatin, and azithromycin. J Clin Rheumatol. 2011;17(1):28-30.

68. Burns CM, Wortmann RL. Gout therapeutics: new drugs for an old disease. Lancet. 2011;377(9760):165-177. 
69. Tausche AK, Richter K, Grassler A, Hansel S, Roch B, Schroder HE. Severe gouty arthritis refractory to anti-inflammatory drugs: treatment with anti-tumour necrosis factor alpha as a new therapeutic option. Ann Rheum Dis. 2004;63(10):1351-1352.

70. Perez-Ruiz F, Lioté F. Lowering serum uric acid levels: what is the optimal target for improving clinical outcomes in gout? Arthritis Rheum. 2007;57(7):1324-1328.

71. Jordan KM, Cameron JS, Snaith M, et al. British Society for Rheumatology and British Health Professionals in Rheumatology guideline for the management of gout. Rheumatology (Oxford). 2007;46(8): 1372-1374.

72. Zhang W, Doherty M, Bardin T, et al. EULAR evidence based recommendations for gout. Part II: Management. Report of a task force of the EULAR Standing Committee for International Clinical Studies Including Therapeutics (ESCISIT). Ann Rheum Dis. 2006;65(10): 1312-1324.

73. Schumacher HR, Chen LX. The practical management of gout. Cleve Clin J Med. 2008;75 Suppl 5:S22-S25.

74. Solomon DH, Avorn J, Levin R, Brookhart MA. Uric acid lowering therapy: prescribing patterns in a large cohort of older adults. Ann Rheum Dis. 2008;67(5):609-613.

75. Briesacher BA, Andrade SE, Fouayzi H, Chan KA. Comparison of drug adherence rates among patients with seven different medical conditions. Pharmacotherapy. 2008;28(4):437-443.

76. Chung Y, Lu CY, Graham GG, Mant A, Day RO. Utilization of allopurinol in the Australian community. Intern Med J. 2008;38(6): 388-395.

77. Chao J, Terkeltaub R. A critical reappraisal of allopurinol dosing, safety and efficacy for hyperuricemia in gout. Curr Rheumatol Rep. 2009;11(2):135-140.

78. Yamanaka H, Togashi R, Hakoda M, et al. Optimal range of serum urate concentrations to minimize risk of gouty attacks during antihyperuricemic treatment. Adv Exp Med Biol. 1998;431:13-18.

79. Borstad GC, Bryant LR, Abel MP, Scroggie DA, Harris MD, Alloway JA. Colchicine for prophylaxis of acute flares when initiating allopurinol for chronic gouty arthritis. J Rheumatol. 2004;31(12):2429-2432.

80. Reinders MK, van Roon EN, Jansen TL, et al. Efficacy and tolerability of urate-lowering drugs in gout: a randomised trial of benzbromarone versus probenecid after failure of allopurinol. Ann Rheum Dis. 2009;68(1):51-56.

81. Becker MA, Schumacher HR, Wortmann RL, et al. Febuxostat compared with allopurinol in patients with hyperuricemia and gout. $N$ Engl J Med. 2005;353(23):2450-2461.

82. Reinders MK, Haagsma C, Van Roon EN, et al. Dose-escalation of allopurinol versus benzbromarone in gout patients: a randomised controlled trial. EULAR Congress, Paris. 2009:OP-0157.

83. Lee MH, Graham GG, Williams KM, Day RO. A benefit-risk assessment of benzbromarone in the treatment of gout. Was its withdrawal from the market in the best interest of patients? Drug Saf. 2008;31(8): 643-665.
84. Dalbeth N, Stamp L. Allopurinol dosing in renal impairment: walking the tightrope between adequate urate lowering and adverse events. Semin Dial. 2007;20(5):391-395.

85. Hande KR, Noone RM, Stone WJ. Severe allopurinol toxicity. Description and guidelines for prevention in patients with renal insufficiency. Am J Med. 1984;76(1):47-56.

86. Dalbeth N, Kumar S, Stamp L, Gow P. Dose adjustment of allopurinol according to creatinine clearance does not provide adequate control of hyperuricemia in patients with gout. J Rheumatol. 2006;33(8): $1646-1650$

87. Panomvana D, Sripradit, Angthararak S. Higher therapeutic plasma oxypurinol concentrations might be required for gouty patients with chronic kidney disease. J Clin Rheumatol. 2008;14(1):6-11.

88. Lee HY, Ariyasinghe JT, Thirumoorthy T. Allopurinol hypersensitivity syndrome: a preventable severe cutaneous adverse reaction? Singapore Med J. 2008;49(5):384-387.

89. Halevy S, Ghislain PD, Mockenhaupt M, et al. Allopurinol is the most common cause of Stevens-Johnson syndrome and toxic epidermal necrolysis in Europe and Israel. J Am Acad Dermatol. 2008; 58(1):25-32.

90. Vazquez-Mellado J, Morales EM, Pacheco-Tena C, Burgos-Vargas R. Relation between adverse events associated with allopurinol and renal function in patients with gout. Ann Rheum Dis. 2001;60(10):981-983.

91. Schumacher HR, Becker MA, Lloyd E, MacDonald PA, Lademacher C. Febuxostat in the treatment of gout: 5-yr findings of the FOCUS efficacy and safety study. Rheumatology (Oxford). 2009;48(2):188-194.

92. Becker MA, Schumacher HR, Wortmann RL, et al. Febuxostat, a novel nonpurine selective inhibitor of xanthine oxidase: a twenty-eight-day, multicenter, phase II, randomized, double-blind, placebo-controlled, dose-response clinical trial examining safety and efficacy in patients with gout. Arthritis Rheum. 2005;52(3):916-923.

93. Edwards NL. Febuxostat: a new treatment for hyperuricaemia in gout. Ipsen sponsored symposium, EULAR Congress, Paris. June 13, 2008 .

94. Arthritis Drugs Advisory Committee Meeting. Department of Health and Human Services, United States Food and Drug Administration Center for Drug Evaluation and Research. November 24, 2008.

95. Chohan S. Safety and efficacy of febuxostat treatment in subjects with gout and severe allopurinol adverse reactions. J Rheumatol. 2011;38(9):1957-1959.

96. Oldfield V, Perry CM. Rasburicase: a review of its use in the management of anticancer therapy-induced hyperuricemia. Drugs. 2006; 66(4):529-545.

97. Richette P, Briere C, Hoenen-Clavert V, Loeuille D, Bardin T. Rasburicase for tophaceous gout not treatable with allopurinol: an exploratory study. J Rheumatol. 2007;34(10):2093-2098.

98. Sundy JS, Baraf HS, Yood RA, et al. Efficacy and tolerability of pegloticase for the treatment of chronic gout in patients refractory to conventional treatment: two randomized controlled trials. JAMA. 2011;306(7):711-720.
Open Access Rheumatology Research and Reviews

\section{Publish your work in this journal}

Open Access Rheumatology Research and Reviews is an international, peer-reviewed, open access journal, publishing all aspects of clinical and experimental rheumatology in the clinic and laboratory including the following topics: Pathology, pathophysiology of rheumatological diseases; Investigation, treatment and management of rheumatological

\section{Dovepress}

diseases; Clinical trials and novel pharmacological approaches for the treatment of rheumatological disorders. The manuscript management system is completely online and includes a very quick and fair peerreview system, which is all easy to use. Visit http://www.dovepress.com/ testimonials.php to read real quotes from published authors. 